\title{
Influence of sample temperature and environmental humidity on measurements of benzene in ambient air by transportable GC-PID
}

\author{
Cristina Romero-Trigueros ${ }^{1}$, Marta Doval Miñarro ${ }^{2}$, Esther González Duperón ${ }^{1}$, and Enrique González Ferradás ${ }^{1}$ \\ ${ }^{1}$ Chemical Engineering Department, School of Chemistry, University of Murcia, 30100 Murcia, Spain \\ ${ }^{2}$ Chemical and Environmental Engineering Department, Technical University of Cartagena, Paseo Alfonso XIII, 52, \\ 30203 Cartagena, Murcia, Spain
}

Correspondence to: Marta Doval Miñarro (marta.doval@upct.es)

Received: 4 April 2017 - Discussion started: 23 May 2017

Revised: 14 September 2017 - Accepted: 18 September 2017 - Published: 27 October 2017

\begin{abstract}
Calibration of in situ analysers of air pollutants is usually done with dry standards. In this paper, the influence of sample temperature and environmental humidity on benzene measurements by gas chromatography coupled with a photoionisation detector (GC-PID) is studied. Two reference gas mixtures ( 40 and $5 \mu \mathrm{g} \mathrm{m}^{-3}$ nominal concentration benzene in air) were subjected to two temperature cycles $\left(20 / 5 / 20^{\circ} \mathrm{C}\right.$ and $\left.20 / 35 / 20^{\circ} \mathrm{C}\right)$ and measured with two identical GC-PIDs. The change in sample temperature did not produce any significant change in readings. Regarding ambient humidity, the chromatographs were calibrated for benzene with dry gases and subjected to measure reference standards with humidity $\left(20\right.$ and $80 \%$ at $20^{\circ} \mathrm{C}$ ). When measuring a concentration of $0.5 \mu \mathrm{g} \mathrm{m}^{-3}$ benzene in air, the levels of humidity tested did not produce any significant interference in measurements taken with any of the analysers. However, when measuring a concentration of $40 \mu \mathrm{g} \mathrm{m}^{-3}$, biases in measurements of 18 and $21 \%$ for each respective analyser were obtained when the relative humidity of the sample was $80 \%$ at $20^{\circ} \mathrm{C}$. Further tests were carried out to study the nature of this interference. Results show that humidity interference depends on both the amount fractions of water vapour and benzene. If benzene concentrations in an area are close to its annual limit value $\left(5 \mu \mathrm{g} \mathrm{m}^{-3}\right)$, biases of $2.2 \%$ can be expected when the absolute humidity is $8.6 \mathrm{~g} \mathrm{~cm}^{-3}$ - corresponding to a relative humidity of $50 \%$ at $20^{\circ} \mathrm{C}$. This can be accounted for in the uncertainty budget of measurements with no need for corrections. If benzene concentrations are above the annual limit value, biases become higher. Thus, in these cases, actions should be taken to reduce the humidity interference,
\end{abstract}

as an underestimation of benzene concentrations may cause a mismanagement of air quality in these situations.

\section{Introduction}

Benzene is one of the species regulated in the European Union (EU) in air quality by Directive 2008/50/EC (EU, 2008). Its harmful health effects have been studied during the last 5 decades (Bahadar et al., 2014; Gist and Burg, 1997; Haley, 1977; Smith, 2010). Evidence for an association with childhood leukaemia (D'Andrea and Reddy, 2016a) and alterations in hematologic and liver profiles in adults (D'Andrea and Reddy, 2016b) is lately growing. The major source of benzene in cities is gasoline, as it is one of its components as well as a product of its combustion (von Schneidemesser et al., 2010).

Continuous measurements of benzene concentrations in air monitoring stations are carried out using automated pumped sampling with in situ gas chromatography. This analytical method must comply with the requirements of Standard EN 14662-3:2015 (EN, 2015). After separation of the organic components, they are usually quantified by a flame ionisation detector (FID) - not selective for BTEX (benzene, toluene, ethylbenzene and xylenes) - or by a photoionisation detector (PID) - a more selective one for aromatics. Liaud et al. (2014) recently compared the performance of a transportable gas chromatograph coupled to a photoionisation detector (GC-PID) to an automated thermal desorber supplied with gas chromatography coupled to a flame ionisation detector (ATD-GC-FID). This study revealed that the 
transportable GC-PID was the most sensitive technique, allowing an efficient separation and quantification of the six BTEX compounds in $12 \mathrm{~min}$.

PIDs consist of an ultraviolet lamp which produces highenergy photons that collide with the molecules of the target gas and ionise them, as long as their ionisation potentials are below the energy of the photons (Peng et al., 2010). PIDs are compact yet they exhibit high performance, featuring excellent response characteristics and detection sensitivity on a ppb scale (Peng et al., 2010). As main drawbacks, they have been reported high power consumption and susceptibility to humidity (Barksy et al., 1985; Peng et al., 2010).

There are several works in the literature that assess the performance of the PID to measure volatile organic compounds (Adamia et al., 1991; Barksy et al., 1985; Coy et al., 2000; LeBouf et al., 2013; Mouradian and Flannery, 1994). However, most of them are related to measurement of species in work places. Occupational concentrations of pollutants are usually at $\mathrm{mg} \mathrm{m}^{-3}$ levels, whereas regulated concentrations of ambient air pollutants are, in most cases, at $\mu \mathrm{g} \mathrm{m}^{-3}$ levels. Particularly, the European annual limit value for benzene is $5 \mu \mathrm{g} \mathrm{m}^{-3}$ (EU, 2008). These low concentrations require a specific assessment of the influence of the environmental conditions on measurements of benzene in air. In a recent paper by the authors, the influence of pressure on benzene measurements by GC-PID was studied (Romero-Trigueros et al., 2016). In this work, we focus on the influence of sample temperature and humidity on ambient measurements of benzene obtained with a commercial transportable GC-PID. Although the instrument that we test also measures toluene, ethylbenzene and xylenes, in this work we only focus on benzene because it is currently the only VOC with limit values in air quality.

\section{Materials and methods}

\subsection{Experimental set-up}

The influence of sample temperature and humidity was studied with two identical type-approved on-site BTEX Syntech Spectras GC955 chromatographs, named analysers I and II, equipped with photoionisation detectors. The air sample is forced through a built-in preconcentration system. Hydrocarbons are preconcentrated on Tenax GR, thermically desorbed and separated on an AT-5 capillary column $(15 \mathrm{~m}$ length $\times 0.32 \mathrm{~mm}$ i.d. $\times 1 \mu \mathrm{m}$ HELIFLEX coating). Analysers I and II are preconfigured to identify as benzene the signals detected by the PID in the windows 176-212 and 148$182 \mathrm{~s}$, respectively. Each measurement cycle lasts for $15 \mathrm{~min}$.

An in-house designed dynamic dilution system devoted to test analyser performance was used for the generation of known concentrations of benzene in zero air at controlled conditions. This chamber has been described else- where (Romero-Trigueros et al., 2016) and only a brief description is given here.

Purified compressed ambient air was used as zero gas. Humidity was added to a portion of the zero air by means of an in-house designed humidifier (Fig. 1a). The humidifier consists of a glass sphere with two lateral inlets ( 1 and 2 ) for the zero air to enter and exit the humidifier, respectively. Water is pumped through a glass tube (3) inserted in a third inlet located at the bottom of the sphere (4). The water impacts the top of the sphere and falls down creating a wet film on the walls which favours the mass transfer. The water is collected at the bottom of the sphere (5) and taken to a container provided with thermal insulation where it is stored. When the system is working, the water from the container is pumped to the humidifier through a thermostatic bath where its temperature is readjusted. The whole system is leak-tested and relative humidities up to $99 \%$ are attainable, depending on the temperatures of the zero air and the humidifying water, and the ratio of zero air flow rate through the humidifier to the flow rate of dry zero air. In Fig. 1b a schematic of the humidifying system integrated in one of the lines of dry zero air is shown.

Sample relative humidity $(\mathrm{RH})$ and temperature were measured with a Testo 645 thermo-hygrometer (precision $\pm 1 \%$ ). From these values, the humidity mixing ratio, $W-$ the ratio of the actual mass of water vapour present in the sample to the mass of the dry air - was derived. The water vapour flow rate, $q_{\mathrm{H}_{2} \mathrm{O}}\left(\mathrm{L} \mathrm{min}^{-1}\right)$, added to the flow of zero air, $q_{\mathrm{z}}\left(\mathrm{L} \min ^{-1}\right)$, was calculated using Eq. (1), where 28.8 and 18 are the molar masses of dry air and water, respectively, in $\mathrm{g} \mathrm{mol}^{-1}$. It is important to know this flow so that the final concentration of benzene in the reference mixture is calculated accounting for it. Thus, any decrease in benzene measurements when measuring wet samples cannot be attributed to the dilution effect of water vapour.

$q_{\mathrm{H}_{2} \mathrm{O}}=W \cdot q_{\mathrm{z}} \cdot \frac{28.8}{18}$

A high-concentration mixture of benzene in nitrogen $\left(1000 \mu \mathrm{g} \mathrm{m}^{-3}\right.$ nominal concentration, $5 \%$ expanded uncertainty) from a gas cylinder (Abelló Linde, Spain) was mixed with the humidified zero air to attain the experimental concentrations required. The gas mixture was certified by Abelló Linde according to Standard ISO 6141:2007. The flow of gas in each branch (Fig. 1b) was controlled and measured with Bronkhorst mass flow controllers (ranges of $0-0.4 \mathrm{~L} \mathrm{~min}^{-1}$ for the benzene in nitrogen mixture and $0-12 \mathrm{~L} \mathrm{~min}^{-1}$ for the zero air). The mass flow controllers are at least annually calibrated against a Gilian Gilibrator (a NIOSH primary standard air flow calibrator) available in our lab.

Sample temperature was changed and controlled by flowing the sample through an in-house thermostatic bath. The whole piping system right after the thermostatic bath - which included the mass flow controllers, the humidifier, the mixing area and the sampling manifold - was set up inside a 

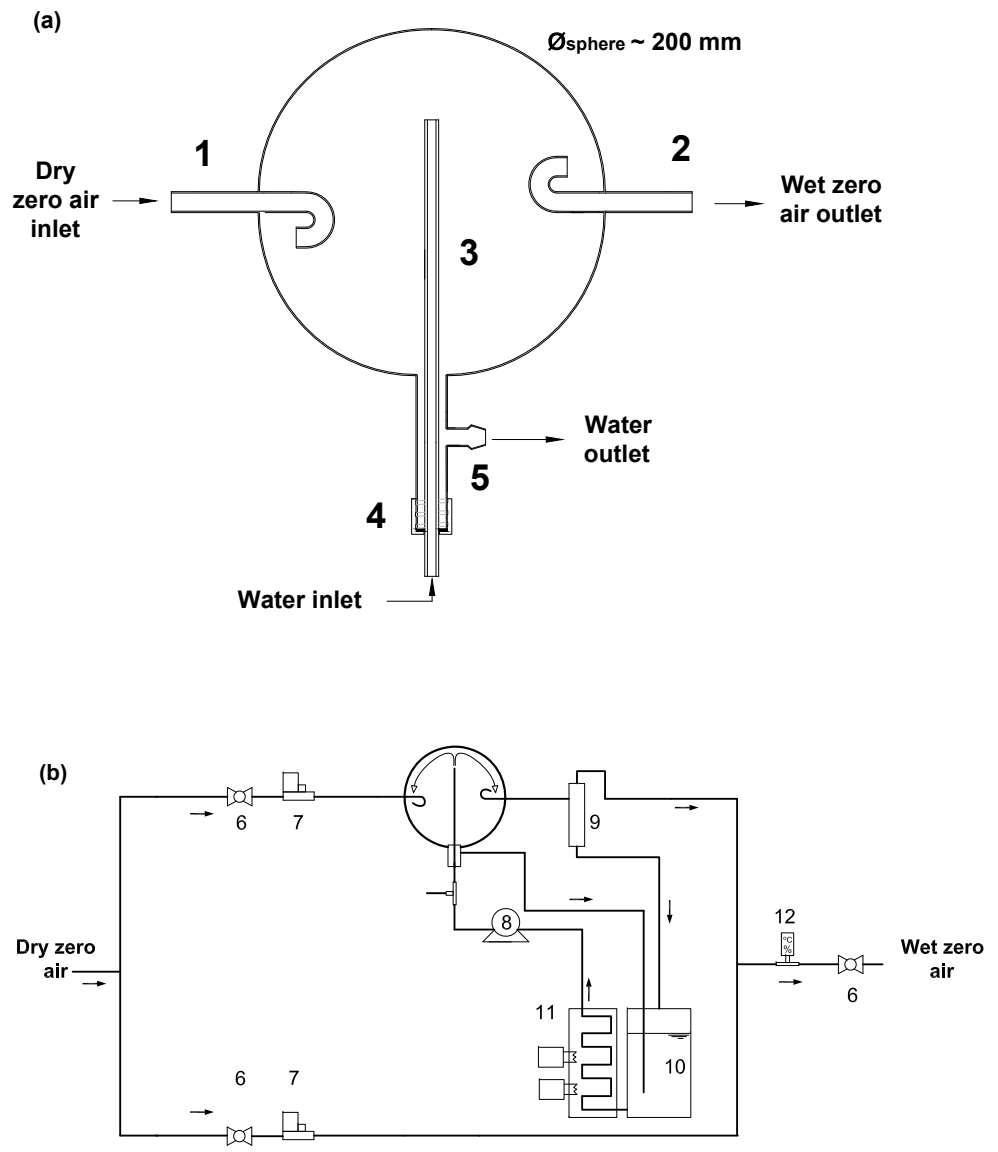

Figure 1. Schematic of the (a) humidifier and (b) the elements that comprise the humidifying system used in this work. (1) Dry zero air inlet; (2) wet zero air outlet; (3) and (4) water inlet; (5) water outlet; (6) shut-off valves; (7) mass flow controllers; (8) water pump; (9) cyclone; (10) water container; (11) thermostatic bath; (12) thermohygrometer.

thermally controlled chamber to maintain the sample temperature. Sample inlet pressure was set up to be equal to normal atmospheric one $(101.3 \pm 0.2 \mathrm{kPa})$. Control of ambient conditions is pivotal to ensure that changes on measurements are due to the effect of the environmental parameter under test and not to other environmental conditions.

\subsection{Experimental methods}

\subsubsection{Calibration}

The analysers used in this work have three different calibration options, namely, a linear calibration using a leastsquares regression, a calibration line forced through the origin and a non-linear regression. All three calibration options were tested with eight different mixtures of benzene in air with concentrations ranging from 0.0 to $47.2 \mu \mathrm{g} \mathrm{m}^{-3}(0.0$, $0.65,2.60,5.20,10.4,15.6,26.3,36.7$ and $47.2 \mu \mathrm{g} \mathrm{m}^{-3}$ ). Thus, three calibration curves were obtained and the squared sum of residuals of the concentration tested was obtained for each calibration. The lowest sum of squares (1.16) was obtained with the non-linear (quadratic) calibration, fol- lowed by the least-squares regression (1.66) and the linear regression forced through the origin (1.78). Therefore, the quadratic option was chosen every time the analysers were calibrated. Calibration was performed at $20^{\circ} \mathrm{C}$ and using dry gases.

\subsubsection{Design of experiments to study the influence of sample temperature on the analyser readings}

In order to study the influence of sample temperature on the analysers, two reference gas mixtures ( 40 and $5 \mu \mathrm{g} \mathrm{m}^{-3}$ nominal concentration) were measured with analysers I and II at different temperatures. Two temperature cycles were performed. First cycle was performed at $20^{\circ} \mathrm{C}$, then changed to $5^{\circ} \mathrm{C}$ and back to $20^{\circ} \mathrm{C}$ (temperature control precision $\pm 2{ }^{\circ} \mathrm{C}$ ). The second one was performed at $20^{\circ} \mathrm{C}$, then changed to $35^{\circ} \mathrm{C}$ and back to $20^{\circ} \mathrm{C}$ again. Once the sample temperature was stabilised, four measurements were taken at each concentration level. 


\subsubsection{Design of experiments to study the influence of humidity on the analyser readings}

\section{First set of experiments}

As a first approach to the subject, the tests described in Standard EN 14662-3:2005 were carried out after calibrating the analysers according to Sect. 2.2.1. These tests were carried out before the release of the 2015 version of the standard and this is why they were performed according to the previous version. These tests consist of measuring a reference mixture of $0.5 \mu \mathrm{g} \mathrm{m}^{-3}$ nominal concentration benzene in air with an $\mathrm{RH}$ of 20 and $80 \%$ at $20^{\circ} \mathrm{C}$ and comparing the results.

Standard EN 14662-3:2005 defines the influence of the RH by means of coefficient $b_{\mathrm{rh}}$, calculated as

$b_{\mathrm{rh}}=\frac{\left|\bar{C}_{\mathrm{rh}, \max }-\bar{C}_{\mathrm{rh}, \min }\right|}{\left|\bar{C}_{\mathrm{rh}, \max }+\bar{C}_{\mathrm{rh}, \min }\right| / 2} \times 10$,

where $\bar{C}_{\text {rh,max }}$ and $\bar{C}_{\text {rh,min }}$ are the average of six consecutive readings when measuring the reference gas mixture $\left(0.5 \mu \mathrm{g} \mathrm{m}^{-3}\right.$ nominal concentration benzene in air) with an 80 and $20 \% \mathrm{RH}$, respectively, at $20^{\circ} \mathrm{C}$. Standard EN $14662-$ 3:2005 establishes that $b_{\mathrm{rh}}$ has to be lower than $4 \%$.

The tests were repeated with a reference mixture of $40 \mu \mathrm{g} \mathrm{m}^{-3}$ nominal concentration benzene in air with the same relative humidities and temperature. A significant difference in readings was noticed when working with the highconcentration reference mixture with both analysers. Further tests with analyser I were then performed to study this phenomenon in depth.

It is worth noting that the test for evaluating the influence of ambient humidity in the new version of the Standard EN 14662, from 2015, has substantially changed. The current version requires testing benzene at the annual limit value with $\mathrm{RH}$ of $80 \%$ at $20^{\circ} \mathrm{C}$ and comparing the measurements with those obtained with the same benzene amount fraction with no humidity. Parameter $b_{\mathrm{rh}}$ is now calculated as

$b_{\text {rh_new }}=\frac{x_{+\mathrm{w}}-x_{-\mathrm{w}}}{c_{\mathrm{w}}}$,

where $x_{+\mathrm{w}}$ is the average of the measurements at concentration of the annual limit value in the presence of water vapour, in $\mu \mathrm{g} \mathrm{m}^{-3} ; x_{-\mathrm{w}}$ is the average of the measurements at concentration of the annual limit value in the absence of water vapour, in $\mu \mathrm{g} \mathrm{m}^{-3}$; and $c_{\mathrm{w}}$ is the water vapour concentration of the test $\left(19 \mathrm{mmol} \mathrm{mol}^{-1}\right)$. Calculated parameter $b_{\text {rh_new }}$ has to be $\left.\leq 0.015 \mu \mathrm{g} \mathrm{m}^{-3} \mathrm{mmol}^{-1} \mathrm{~mol}\right)$. It is interesting to note that this test is not carried out anymore at $40 \mu \mathrm{g} \mathrm{m}^{-3}$.

\section{Second set of experiments}

An in-depth study of the influence of humidity on measurements was carried out by measuring several reference mixtures of benzene in air $\left(5 \mu \mathrm{g} \mathrm{m}^{-3}\right.$ nominal concentration) with different absolute humidity $(\mathrm{AH})$ values ranging from 0 to $32 \mathrm{~g} \mathrm{~m}^{-3}$. These tests were repeated with a reference mixture of $40 \mu \mathrm{g} \mathrm{m}^{-3}$ nominal concentration of benzene in air.

Humidity in the range $0-17 \mathrm{~g} \mathrm{~m}^{-3}$ was obtained at $20^{\circ} \mathrm{C}$ and $\mathrm{RH}$ ranging from 0 to $99 \%$. Higher $\mathrm{AH}$ was attained increasing the working temperature to $35^{\circ} \mathrm{C}$. Results in Sect. 3.1 showed that sample temperature inside the tested range did not influence benzene measurements. Thus, this parameter can be changed in order to achieve a high $\mathrm{AH}$ in the samples.

\section{Results and discussion}

\subsection{Influence of sample temperature on benzene measurements}

As mentioned in Sect. 2.2.2, a test to evaluate the influence of sample temperature was carried out. The reason for this was to know whether this parameter affects the readings. If it were not the case, temperature could be changed during the tests and, therefore, the maximum $\mathrm{AH}$ tested would not be limited by the saturation humidity of the sample at $20^{\circ} \mathrm{C}$. Table 1 shows the results of the tests when analyser I measured two reference gas mixtures ( 40 and $5 \mu \mathrm{g} \mathrm{m}^{-3}$ nominal concentration benzene in air) subjected to two temperature cycles $\left(20 / 5 / 20^{\circ} \mathrm{C}\right.$ and $\left.20 / 35 / 20^{\circ} \mathrm{C}\right)$. Similar results were obtained for analyser II. As it can be seen, the change in sample temperature did not produce any significant change in readings and, thus, temperature was increased to $35^{\circ} \mathrm{C}$ in some of the tests in order to work with a higher $\mathrm{AH}$ in our reference gas mixtures. The non-dependence of measurements on sample temperature can be explained by the fact that the sample is heated initially in the oven to $50^{\circ} \mathrm{C}$, the initial temperature of the sample being irrelevant in the whole process.

\subsection{Compliance with the requirements of EN 14662-3:2005}

Table 2 summarises the results obtained when carrying out the tests described in "First set of experiments". Whereas humidity does not have a significant influence on readings at $0.5 \mu \mathrm{g} \mathrm{m}^{-3}$ level, it does at $40 \mu \mathrm{g} \mathrm{m}^{-3}$ (calculated $b_{\mathrm{rh}}$ coefficients of 18 and $21 \%$ for analyser I and II, respectively). This is a negative influence; that is, readings are lower than expected when the $\mathrm{RH}$ increases for a constant temperature. Moreover, the calculated coefficient $b_{\text {rh }}$ for both analysers turned out to be higher than $4 \%$ (the maximum variation allowed in the Standard EN 14662-3:2005) when the tests were carried out with $40 \mu \mathrm{g} \mathrm{m}^{-3}$ of benzene in air. In order to study deeper this phenomenon, the tests described in "Second set of experiments" were carried out and the results are shown in Sect. 3.3. Compliance of analyser I with the requirements of the new standard was calculated from a set of results in Table $3\left(T=20^{\circ} \mathrm{C}, \mathrm{RH}=81 \%, C_{\text {ref }}=C_{-\mathrm{w}}=5.31 \mu \mathrm{g} \mathrm{m}^{-3}\right.$, 
Table 1. Analyser I readings when subjected to changes in sample temperature. In parentheses, the standard deviation of the measurements.

\begin{tabular}{lrrr}
\hline Temperature cycle & $20^{\circ} \mathrm{C}$ & $5{ }^{\circ} \mathrm{C}$ & $20^{\circ} \mathrm{C}$ \\
\hline $\begin{array}{l}\text { Average reading of concentration }\left(\mu \mathrm{g} \mathrm{m}^{-3}\right) \\
\text { when measuring a benzene concentration of }\end{array}$ & $39.96(0.45)$ & $39.69(0.26)$ & $39.82(0.29)$ \\
$\begin{array}{l}39.96 \pm 0.30 \mu \mathrm{g} \mathrm{m}^{-3} \\
\text { Average reading of concentration }\left(\mu \mathrm{g} \mathrm{m}^{-3}\right) \\
\text { when measuring a benzene concentration of } \\
4.77 \pm 0.08 \mu \mathrm{g} \mathrm{m}^{-3}\end{array}$ & $4.77(0.08)$ & & \\
\hline $\begin{array}{l}\text { Temperature cycle } \\
\text { Average reading of concentration }\left(\mu \mathrm{g} \mathrm{m}^{-3}\right)\end{array}$ & $39.82(0.29)$ & $39.78(0.50)$ & $39.87(0.25)$ \\
$\begin{array}{l}\text { when measuring a benzene concentration of } \\
39.96 \pm 0.30 \mu \mathrm{g} \mathrm{m}^{-3}\end{array}$ & & & \\
$\begin{array}{l}\text { Average reading of concentration }\left(\mu \mathrm{g} \mathrm{m}^{-3}\right) \\
\text { when measuring a benzene concentration of } \\
4.77 \pm 0.08 \mu \mathrm{g} \mathrm{m}^{-3}\end{array}$ & $4.78(0.06)$ & $4.77(0.10)$ & $4.78(0.11)$ \\
& & & \\
\hline
\end{tabular}

Table 2. Analyser readings when subjected to changes in ambient humidity for a constant reference concentration and sensitivity coefficients to humidity ( $b_{\text {rh }}$ and $b_{\text {rh_new }}$ ). Test temperature: $20 \pm 2{ }^{\circ} \mathrm{C}$. In parentheses, the standard deviation of the measurements.

\begin{tabular}{lrr}
\hline Test nominal concentration: $0.5 \mu \mathrm{g} \mathrm{m}^{-3}$ & $\begin{array}{r}\text { Average value } \\
\text { Analyser I } \\
\left(\mu \mathrm{g} \mathrm{m}^{-3}\right)\end{array}$ & $\begin{array}{r}\text { Average value } \\
\text { Analyser II } \\
\left(\mu \mathrm{g} \mathrm{m}^{-3}\right)\end{array}$ \\
\hline $20 \%$ relative humidity & $0.53(0.01)$ & $0.55(0.01)$ \\
$80 \%$ relative humidity & $0.51(0.01)$ & $0.53(0.01)$ \\
$\left.b_{\text {rh }} \%\right)$ & 3.1 & 3.9 \\
\hline Test nominal concentration: $40 \mu \mathrm{g} \mathrm{m}^{-3}$ & & \\
\hline $20 \%$ relative humidity & $44.3(0.17)$ & $46.7(0.47)$ \\
$80 \%$ relative humidity & $36.9(0.23)$ & $37.9(0.18)$ \\
$b_{\text {rh }}(\%)$ & 18.2 & 20.8 \\
\hline Test nominal concentration: $5 \mu \mathrm{g} \mathrm{m}^{-3}$ & & \\
\hline $0 \%$ relative humidity & $5.31(0.06)$ & \\
$80 \%$ relative humidity & $4.99(0.07)$ & \\
$b_{\text {rh_new }}\left(\mu \mathrm{g} \mathrm{m}{ }^{-3}\right.$ mmol $\left.^{-1} \mathrm{~mol}\right)$ & 0.0175 & \\
\hline
\end{tabular}

$\left.C_{\text {meas }}=C_{+\mathrm{w}}=4.99, \quad C_{\mathrm{w}}=18.3 \mathrm{mmol} \mathrm{mol}^{-1}\right) . \quad$ A value of $b_{\text {hr_new }}$ equal to $0.0175 \mu \mathrm{g} \mathrm{m}^{-3} \mathrm{mmol}^{-1} \mathrm{~mol}$ was obtained, which is higher than the new performance criterion $\left(0.015 \mu \mathrm{g} \mathrm{m}^{-3} \mathrm{mmol}^{-1} \mathrm{~mol}\right)$. This interference would be even larger if the tests were conducted at $40 \mu \mathrm{g} \mathrm{m}^{-3}$ (see Sect. 3.3). From our perspective, when type-approving GCPID analysers, testing the humidity interference with a value in between the annual limit and the span (e.g. $20 \mu \mathrm{g} \mathrm{m}^{-3}$ ) would be interesting to detect important biases at high benzene amount fractions, which can be present, for instance, in industrial areas or close to petrol stations.

\subsection{Influence of humidity on benzene measurements}

Table 3 summarises the humidity conditions, the reference concentration of benzene generated (after considering the dilution effect of water vapour), the average reading of analyser I and the calculated relative difference from the reference concentration of each test. These differences were plotted against the AH of the test in Fig. 2.

There is a clear linear relationship between analyser readings and $\mathrm{AH}$. For a given benzene amount fraction, the higher the $\mathrm{AH}$ in the sample is, the lower the chromatograph readings are. This result was previously obtained by Barksy et al. (1985) but using concentrations of volatile organic compounds at ppm levels.

The data in Fig. 2 were fitted by linear leastsquares regression, which gave the following equations: $\quad E=-1.066 \cdot \mathrm{AH}+4.783 \quad\left(r^{2}=0.91\right) \quad$ and $E=-1.557 \cdot \mathrm{AH}-3.341\left(r^{2}=0.94\right)$ for nominal reference benzene concentrations of 5 and $40 \mu \mathrm{g} \mathrm{m}^{-3}$, respectively. $E$ is the relative difference between the reference concentration generated in the test chamber and the analyser reading. Differences between the slopes were studied to find out whether they were significantly different; for this, we used a $t$ value calculated from $t=\left(m_{1}-m_{2}\right) / \operatorname{SE}\left(m_{1}-m_{2}\right)$, where $m_{1}$ and $m_{2}$ are the slopes of the two straight lines compared and $\operatorname{SE}\left(m_{1}-m_{2}\right)$ is the standard error of the difference, calculated as the square root of the quadratic sum of the standard error of each slope. A $t$ value of 2.272 was obtained. This value was higher than the critical one $(2.145)$ for $\mathrm{p}=0.05$ and 14 degrees of freedom $\left(\mathrm{df}=\left(n_{1}-2\right)+\left(n_{2}-2\right)\right.$, where $n_{1}$ and $n_{2}$ are the number of data in the least-square regressions of Fig. 2), which meant that the difference in the slopes was significant and could not be attributed to random measurement error. This is interesting as it shows that the variation of readings by effect of ambient humidity is more pronounced at higher ambient ratios of benzene. Moreover, 


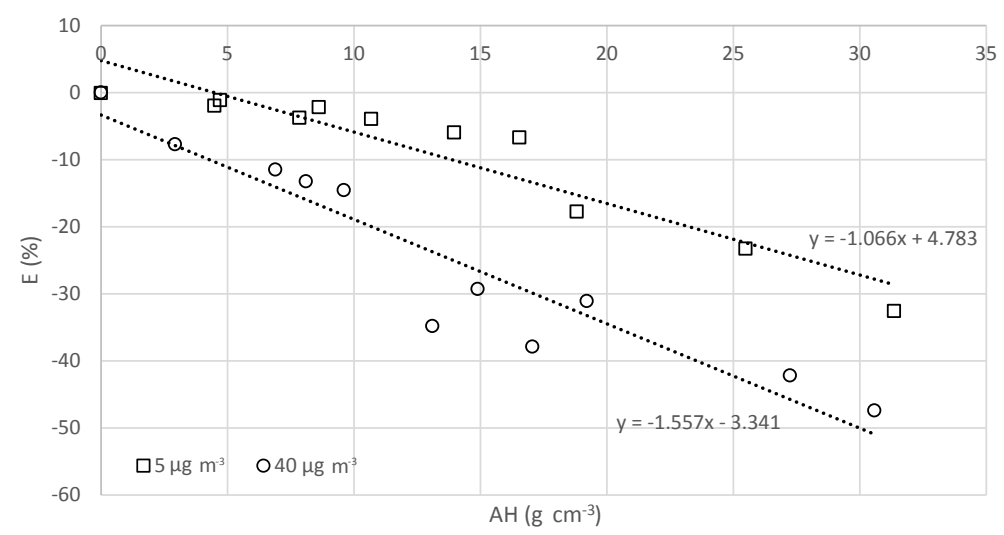

Figure 2. Relative differences in readings from the reference value of concentration as a function of the absolute humidity of the sample.

higher concentrations of benzene are more affected by ambient water vapour as for the same $\mathrm{AH}$, relative differences are higher in the tests at $40 \mu \mathrm{g} \mathrm{m}^{-3}$ than at $5 \mu \mathrm{g} \mathrm{m}^{-3}$.

For $35^{\circ} \mathrm{C}$ and $80 \% \mathrm{RH}$ (approx. $31 \mathrm{~g} \mathrm{~m}^{-3} \mathrm{AH}$ ) the bias in readings was 33 and $47 \%$ for a reference concentration of benzene in air of 5 and $40 \mu \mathrm{g} \mathrm{m}^{-3}$, respectively. These conditions, although a bit extreme, can easily occur in many locations (e.g. Mediterranean areas in summer). Less extreme conditions can also have an important bias in readings (for instance, at $20^{\circ} \mathrm{C}$ and $50 \% \mathrm{RH}$ there is a $2.2 \%$ bias in the concentration readings at $5 \mu \mathrm{g} \mathrm{m}^{-3}$ level and $13 \%$ at $40 \mu \mathrm{g} \mathrm{m}^{-3}$ ). Considering a location where mean annual benzene concentrations are close to the annual limit value $\left(5 \mu \mathrm{g} \mathrm{m}^{-3}\right)$, a bias in measurements of approximately $2 \%$ can be easily expected due to a water vapour mixing ratio close to $8.6 \mathrm{~g} \mathrm{~cm}^{-3}$. This bias can be acceptable, taking into consideration that benzene data quality objective in current legislation for fixed measurements is $25 \%$. Thus, it should be incorporated to the uncertainty budget of the measurements with no need for further corrections. Moreover, if ambient concentrations are below the annual limit value, the interference of environmental humidity, although not negligible, will not change the air quality situation of that area. However, if benzene ambient ratios are above, measurements will be systematically underestimated by effect of ambient humidity, precisely in those areas where a stricter control of concentrations is required. It could be the case of a location that apparently meets the air quality limits because concentrations are underestimated but, in reality, its environmental situation is not acceptable. Thus, it is in these cases where humidity interference on measurements should be addressed. Areas with concentrations of benzene above the annual limit value are widely reported in the literature (Anttila et al., 2016; Bruinen De Bruin et al., 2008; Licen et al., 2016; Al Madhoun et al., 2011).

In our tests, the baseline did not change when zero gas with different amount fractions of water vapour was measured. The peak shapes and the elution times did not change either when measuring a constant amount fraction of benzene with different amount fractions of humidity. This led us to think that water vapour does not interfere in the preconcentration and separation steps and the PID is the part of the instrument most affected by the humidity.

The effect of humidity on PID performance has been proved to be double (MSA, 2005). Despite the ionising potential of water vapour being higher than the energy of the PID, it can produce a small background signal at high noncondensing $\mathrm{RH}$, overestimating VOC concentrations. The second effect is the quenching of part of the UV light. When the analysers have been calibrated with dry gases and they measure a sample with humidity, the water vapour molecules in the sample absorb part of the UV radiation emitted. For a given concentration of benzene, the higher the $\mathrm{AH}$ in the sample the higher the absorption of UV radiation and the less energy available to ionise the molecules of benzene. This bias depends not only on the water vapour concentration but also on the benzene one, as we have checked in our tests. For a given concentration of humidity, if the concentration of benzene is very low (e.g. $0.5 \mu \mathrm{g} \mathrm{m}^{-3}$ ) the residual UV radiation, that is, the radiation not absorbed by the water vapour, is enough to ionise and, therefore, quantify all the molecules of benzene in the sample. This seems to be the case of the tests conducted in Sect. 3.1 at $0.5 \mu \mathrm{g} \mathrm{m}^{-3}$, as no effect was observed when changing the amount fraction of water vapour in the reference mixture. However, as the amount fraction of benzene increases, the residual UV radiation may not be able to ionise all the molecules of benzene, as it is apparently happening with the samples with 5 and $40 \mu \mathrm{g} \mathrm{m}^{-3}$ benzene in air. From these two effects - background signal and radiation quenching - the latter seems to be the most influencing; there is a decrease in readings with humidity and not an increase as would be expected from a background signal effect.

A third phenomenon may be occurring as well. The benzene radical cation formed after ionisation of benzene can react with water to give hydroxycyclohexadienyl radical, which in turn can dissociate to benzene and $\mathrm{OH}$ radicals 
Table 3. Relative (RH) and absolute (AH) humidity, mass fraction of water vapour in the dry air $(W)$, reference concentration of benzene $\left(C_{\text {ref }}\right)$, average reading of analyser I $\left(C_{\text {meas }}\right)$ and relative difference between measurements and reference values $(E) . q_{\mathrm{t}}$ is the total flow rate, calculated as the sum of the flow rate of zero air $\left(q_{\mathrm{z}}\right)$, water vapour $\left(q_{\mathrm{H}_{2} \mathrm{O}}\right)$ and the flow rate from the benzene reference gas mixture $\left(q_{\text {std }}\right) . C_{\text {std }}$ is the amount fraction of benzene in the gas cylinder.

\begin{tabular}{|c|c|c|c|c|c|c|c|}
\hline $\begin{array}{l}\mathrm{RH} \\
(\%)\end{array}$ & $\begin{array}{r}\mathrm{AH} \\
\left(\mathrm{g} \mathrm{cm}^{-3}\right)\end{array}$ & $\begin{array}{r}W \\
\left(\mathrm{~g} \mathrm{H}_{2} \mathrm{Og} \mathrm{g}^{-1}\right. \\
\text { dry air) }\end{array}$ & $\begin{array}{r}q \mathrm{H}_{2} \mathrm{O} \\
\left(\mathrm{L} \mathrm{min}^{-1}\right)\end{array}$ & $\begin{array}{r}q_{\mathrm{t}} \\
\left(\mathrm{L} \mathrm{min}^{-1}\right)\end{array}$ & $\begin{array}{r}C_{\mathrm{ref}} \\
\left(\mu \mathrm{g} \mathrm{m}^{-3}\right)\end{array}$ & $\begin{array}{r}C_{\text {meas }} \\
\left(\mu \mathrm{g} \mathrm{m}^{-3}\right)\end{array}$ & $\begin{array}{r}E \\
(\%)\end{array}$ \\
\hline \multicolumn{8}{|c|}{$\begin{array}{c}T=20 \pm 2{ }^{\circ} \mathrm{C} ; C_{\mathrm{std}}=1053.5 \pm 26.3 \mu \mathrm{g} \mathrm{m}^{-3} ; q_{\mathrm{z}}=11.636 \pm 0.002 \mathrm{~L} \mathrm{~min}^{-1} \\
q_{\mathrm{std}}=0.05999 \pm 6.265 \times 10^{-5} \mathrm{~L} \mathrm{~min}^{-1}\end{array}$} \\
\hline 0.4 & 0.0689 & $5.74 \times 10^{-5}$ & $1.069 \times 10^{-3}$ & 11.697 & 5.40 & 5.40 & 0.00 \\
\hline 26 & 4.480 & 0.00373 & 0.0695 & 11.765 & 5.37 & 5.27 & -1.95 \\
\hline 50 & 8.616 & 0.00718 & 0.134 & 11.830 & 5.34 & 5.23 & -2.20 \\
\hline 62 & 10.68 & 0.00890 & 0.166 & 11.862 & 5.33 & 5.12 & -3.95 \\
\hline 81 & 13.96 & 0.0116 & 0.217 & 11.913 & 5.31 & 4.99 & -5.94 \\
\hline 96 & 16.54 & 0.0138 & 0.257 & 11.953 & 5.29 & 4.93 & -6.70 \\
\hline \multicolumn{8}{|c|}{$\begin{array}{c}T=35 \pm 2{ }^{\circ} \mathrm{C} ; C_{\mathrm{std}}=1053.5 \pm 26.3 \mu \mathrm{g} \mathrm{m}^{-3} ; q_{\mathrm{z}}=11.637 \pm 0.002 \mathrm{~L} \mathrm{~min}^{-1} \\
q_{\mathrm{std}}=0.05999 \pm 6.265 \times 10^{-5} \mathrm{~L} \mathrm{~min}^{-1}\end{array}$} \\
\hline 0.2 & 0.0345 & $2.871 \times 10^{-5}$ & $5.347 \times 10^{-4}$ & 11.697 & 5.40 & 5.40 & 0.00 \\
\hline 12 & 4.70 & 0.00392 & 0.0730 & 11.769 & 5.37 & 5.31 & -1.12 \\
\hline 20 & 7.84 & 0.00653 & 0.122 & 11.818 & 5.35 & 5.15 & -3.75 \\
\hline 48 & 18.82 & 0.0157 & 0.292 & 11.988 & 5.27 & 4.34 & -17.8 \\
\hline 65 & 25.48 & 0.0212 & 0.395 & 12.091 & 5.23 & 4.01 & -23.3 \\
\hline 80 & 31.36 & 0.0261 & 0.487 & 12.183 & 5.19 & 3.50 & -32.6 \\
\hline \multicolumn{8}{|c|}{$\begin{array}{c}T=25 \pm 2{ }^{\circ} \mathrm{C} ; C_{\mathrm{std}}=1053.5 \pm 26.3 \mu \mathrm{g} \mathrm{m}^{-3} ; q_{\mathrm{z}}=9.099 \pm 0.002 \mathrm{~L} \mathrm{~min}^{-1} \\
q_{\mathrm{std}}=0.3599 \pm 4.125 \times 10^{-4} \mathrm{~L} \mathrm{~min}^{-1}\end{array}$} \\
\hline 1.1 & 0.190 & $1.579 \times 10^{-4}$ & $2.299 \times 10^{-3}$ & 9.461 & 40.07 & 40.08 & 0.02 \\
\hline 17 & 2.929 & 0.00244 & 0.0355 & 9.494 & 39.93 & 36.85 & -7.72 \\
\hline 40 & 6.893 & 0.00574 & 0.0836 & 9.543 & 39.73 & 35.18 & -11.46 \\
\hline 47 & 8.099 & 0.00675 & 0.0983 & 9.557 & 39.67 & 34.43 & -13.21 \\
\hline 76 & 13.10 & 0.0109 & 0.1589 & 9.618 & 39.42 & 25.70 & -34.80 \\
\hline 99 & 17.06 & 0.0142 & 0.207 & 9.666 & 39.23 & 24.37 & -37.87 \\
\hline \multicolumn{8}{|c|}{$\begin{array}{c}T=35 \pm 2{ }^{\circ} \mathrm{C} ; C_{\mathrm{std}}=1053.5 \pm 26.3 \mu \mathrm{g} \mathrm{m}^{-3} ; q_{\mathrm{z}}=9.098 \pm 0.002 \mathrm{~L} \mathrm{~min}^{-1} \\
q_{\mathrm{std}}=0.3599 \pm 4.125 \times 10^{-4} \mathrm{~L} \mathrm{~min}^{-1}\end{array}$} \\
\hline 1.8 & 0.706 & $5.88 \times 10^{-3}$ & $8.56 \times 10^{-3}$ & 9.466 & 40.05 & 40.09 & 0.10 \\
\hline 25 & 9.604 & 0.0080 & 0.117 & 9.574 & 39.60 & 33.83 & -14.56 \\
\hline 38 & 14.90 & 0.0125 & 0.182 & 9.640 & 39.33 & 27.82 & -29.28 \\
\hline 49 & 19.21 & 0.0161 & 0.235 & 9.693 & 39.12 & 26.95 & -31.10 \\
\hline 70 & 27.24 & 0.0229 & 0.333 & 9.791 & 38.72 & 22.38 & -42.20 \\
\hline 78 & 30.57 & 0.0257 & 0.374 & 9.832 & 38.56 & 20.28 & -47.41 \\
\hline
\end{tabular}

(Eberhardt, 1981). This effect is in line with the quenching effect of water vapour as both of them reduce the amount of ionised benzene reaching the electrodes.

There are a few works in the literature that use in situ GCPID to measure benzene in air (Bruno et al., 2001; Kelessis et al., 2006; Villanueva et al., 2012). Bruno et al. (2001) and Villanueva et al. (2012) use gas chromatographs from Syntech Spectras so a study of the influence of humidity in their measurements could be done as long as calibration details and $\mathrm{RH}$ data are provided.
Bruno et al. (2001) mainly focused on source apportionment and they do not provide information related to ambient humidity. The average concentration of benzene during the sampling period was $4 \pm 1.6 \mu \mathrm{g} \mathrm{m}^{-3}$ so measurements were close to the annual limit value but, mainly, below it, so around $2 \%$ bias is expected at $20^{\circ} \mathrm{C}$ and $50 \% \mathrm{RH}$ if calibration was carried out with dry gases. Villanueva et al. (2012) intercompared tropospheric ozone, benzene and toluene by a commercial differential optical absorption spectroscopy (DOAS) and conventional monitoring techniques. The instrument used to measure benzene and toluene was the 
same as the one used in our work. They mention the use of certified gas mixtures to calibrate their instruments. There is no mention to water vapour in the mixtures so it is assumed that they are dry gases. Their results show that average levels for ozone, benzene and toluene obtained with DOAS were higher than those obtained with UV photometry for ozone and GC-PID for the aromatics. The largest differences found are for benzene. Although the water interference found in our work is compatible with the results obtained in Villanueva et al. (2012), it may not explain the whole difference between the analytical techniques used, which is up to $50 \%$ in some cases. A quantification in this paper of the bias in their measurements by GC-PID due to water vapour is not possible due to lack of temperature and RH data.

The influence of humidity on many air quality monitoring techniques has always been a major problem. PID detectors are not the only ones affected. FID were proved to be affected as well (LeBouf et al., 2013); however, these tests were performed at ppm levels. Among the reference measurement techniques to measure air pollutants, both chemiluminescence with ozone to measure $\mathrm{NO}$ and $\mathrm{NO}_{2}$ (Gerboles et al., 2003; Hayden, 2003; Miñarro and Ferradás, 2012; Steinbacher et al., 2007) and UV photometry to measure ozone are also humidity dependent (Wilson and Birks, 2006). Recently, Bluhme et al. (2016) have shown that measurements of $\mathrm{SH}_{2}$ by UV fluorescence are also affected. The interference mechanism is different in each technique but the result is always an underestimation of measurements. Some manufacturers have opted for adding filters or driers to their equipment in order to keep humidity in the sample to a minimum. These implementations have been proved to reduce biases in some cases (Bluhme et al., 2016; Steinbacher et al., 2007; Wilson and Birks, 2006). An alternative to scrubbers, which have the drawback of potentially adsorbing the target molecule, is calibration with wet gases. Ideally, calibration procedures should be done at the same ambient conditions as sampling. Calibration with wet gases may reduce measurement uncertainty due to environmental humidity in many cases. However, a thorough work regarding short- and long-term stability of wet calibration gases in gas cylinders should be first tackled by metrology institutes. Using wet calibration gases obtained by dynamic dilution could bridge the gap and help reduce the uncertainty of benzene measurements and other pollutants in ambient air.

The behaviour observed in this work is likely to be shown by GC-PID instruments by other manufacturers, although to a different extent, which means that benzene concentrations - and, presumably, given the nature of the interference, ethylbenzene, toluene and xylenes concentrations as well may be systematically underestimated. In areas where ambient concentrations of benzene are usually above the annual limit value, the humidity interference on measurements should be urgently addressed. A joint effort from manufacturers, metrology institutes and users is advisable to reduce the bias due to ambient humidity on BTEX measurements obtained by GC-PID - but also on measurements of other atmospheric pollutants - as relievable data are the starting point for a correct environmental management.

\section{Conclusions}

In this work, the influence of sample temperature and ambient humidity on benzene measurements obtained with two automated in situ GC-PIDs is studied. Sample temperature turned out not to influence measurements between 5 and $35^{\circ} \mathrm{C}$. Regarding humidity, one of the chromatographs was calibrated with dry gases, which is nowadays a current practice, and, subsequently, different amount fractions of humidity were added to the reference mixture. The AH tested ranged from 0 to $31 \mathrm{~g} \mathrm{~cm}^{-3}$. The dilution effect of adding water vapour was taken into account in the reference concentration calculation.

When measuring $5 \mu \mathrm{g} \mathrm{m}^{-3}$ of benzene in air, biases in readings ranged from 1 to $32 \%$ depending on the $\mathrm{AH}$ in the gas mixture. For an $\mathrm{AH}$ close to $8.6 \mathrm{~g} \mathrm{~cm}^{-3}$ - corresponding to a $\mathrm{RH}$ of $50 \%$ at $20^{\circ} \mathrm{C}$ - the bias in measurements is about $2.2 \%$. Tests were repeated with a $40 \mu \mathrm{g} \mathrm{m}^{-3}$ benzene in air mixture. In this case, biases of up to $47 \%$ were obtained when the $\mathrm{AH}$ in the sample was $30 \mathrm{~g} \mathrm{~cm}^{-3}$. A less extreme AH in the sample $\left(8 \mathrm{~g} \mathrm{~cm}^{-3}\right)$ produced a bias of approximately $13 \%$. Results show that water vapour interference depends on both the water and benzene amount fractions in the sample.

If the concentrations of benzene in a certain location are far below the annual limit value $\left(5 \mu \mathrm{g} \mathrm{m}^{-3}\right)$, the bias due to water interference can be acceptable, taking into consideration that benzene data quality objective in current legislation for fixed measurements is $25 \%$. Thus, it should be incorporated to the uncertainty budget of the measurements with no need for further corrections. Moreover, if ambient concentrations are below the annual limit value, the interference of environmental humidity, although not negligible, will not change the air quality situation of that area. However, if benzene ambient ratios are above, measurements will be systematically underestimated by effect of ambient humidity, precisely in those areas where a stricter control of concentrations is required. Thus, it is in these cases where humidity interference on measurements should be addressed. Using appropriate scrubbers or wet calibration gases could help reduce measurement uncertainty of benzene and many other air pollutants monitored with analytical techniques also affected by water vapour.

Data availability. The data are available upon request to M. Doval Miñarro (marta.doval@upct.es). 
Competing interests. The authors declare that they have no conflict of interest.

Acknowledgements. We would like to acknowledge the Consejería de Agua, Agricultura y Medio Ambiente of the Comunidad Autónoma de la Región de Murcia for its financial support and for the facilities to carry out this work.

Edited by: Hendrik Fuchs

Reviewed by: two anonymous referees

\section{References}

Adamia, T., Budovich, V., Nevjagskaya, I., Shlyakhov, A., and Jakovlev, S.: Effect of temperature on the sensitivity of the photoionization detector, J. Chromatogr. A, 540, 441-448, https://doi.org/10.1016/S0021-9673(01)88836-1, 1991.

Al Madhoun, W. A., Ramli, N. A., Yahaya, A. S., Yusuf, N. F. F. M., Ghazali, N. A., and Sansuddin, N.: Levels of benzene concentrations emitted from motor vehicles in various sites in Nibong Tebal, Malaysia, Air Qual. Atmos. Heal., 4, 103-109, https://doi.org/10.1007/s11869-010-0083-6, 2011.

Anttila, P., Stefanovska, A., Nestorovska-Krsteska, A., Grozdanovski, L., Atanasov, I., Golubov, N., Ristevski, P., Toceva, M., Lappi, S., and Walden, J.: Characterisation of extreme air pollution episodes in an urban valley in the Balkan Peninsula, Air Qual. Atmos. Heal., 9, 129-141, https://doi.org/10.1007/s11869015-0326-7, 2016.

Bahadar, H., Mostafalou, S., and Abdollahi, M.: Current understandings and perspectives on non-cancer health effects of benzene: A global concern, Toxicol. Appl. Pharmacol., 276, 83-94, https://doi.org/10.1016/j.taap.2014.02.012, 2014.

Barksy, J. B., Hee, S. S. Q., and Clark, C. S.: An Evaluation of the Response of Some Portable, Direct-Reading $10.2 \mathrm{eV}$ and $11.8 \mathrm{eV}$ Photoionization Detectors, and a Flame Ionization Gas Chromatograph for Organic Vapors in High Humidity Atmospheres, Am. Ind. Hyg. Assoc. J., 46, 9-14, https://doi.org/10.1080/15298668591394293, 1985.

Bluhme, A. B., Ingemar, J. L., Meusinger, C., and Johnson, M. S.: Water vapor inhibits hydrogen sulfide detection in pulsed fluorescence sulfur monitors, Atmos. Meas. Tech., 9, 2669-2673, https://doi.org/10.5194/amt-9-2669-2016, 2016.

Bruinen De Bruin, Y., Koistinen, K., Kephalopoulos, S., Geiss, O., Tirendi, S., and Kotzias, D.: Characterisation of urban inhalation exposures to benzene, formaldehyde and acetaldehyde in the European Union: Comparison of measured and modelled exposure data, Environ. Sci. Pollut. Res., 15, 417-430, https://doi.org/10.1007/s11356-008-0013-4, 2008.

Bruno, P., Caselli, M., De Gennaro, G., and Traini, A.: Source apportionment of gaseous atmospheric pollutants by means of an absolute principal component scores (APCS) receptor model, Anal. Bioanal. Chem., 371, 1119-1123, https://doi.org/10.1007/s002160101084, 2001.

Coy, J. D., Bigelow, P. L., Buchan, R. M., Tessari, J. D., and Parnell, J. O.: Field Evaluation of a Portable Photoionization Detector for Assessing Exposure to Solvent Mixtures, Am. Ind. Hyg. Assoc.
J., 61, 268-274, https://doi.org/10.1080/15298660008984536, 2000.

D'Andrea, M. A. and Reddy, G. K.: Adverse Health Effects of Benzene Exposure Among Children Following a Flaring Incident at the British Petroleum Refinery in Texas City, Clin. Pediatr. (Phila)., 55, 219-227, https://doi.org/10.1177/0009922815594358, 2016a.

D'Andrea, M. A. and Reddy, G. K.: Detrimental Health Effects of Benzene Exposure in Adults After a Flaring Disaster at the BP Refinery Plant in Texas City, Disaster Med. Public Health Prep., 10, 233-239, https://doi.org/10.1017/dmp.2015.160, 2016b.

Eberhardt, M. K.: Reaction of benzene radical cation with water. Evidence for the reversibility of hydroxyl radical addition to benzene, J. Am. Chem. Soc., 103, 3876-3878, https://doi.org/10.1021/ja00403a042, 1981.

EN: 14662-3 Ambient air, Standard method for the measurement of benzene concentrations, Automated pumped sampling with in situ gas chromatography, 2015.

EU: Directive 2008/50/EC of the European Parliament and of the Council of 21 May 2008 on ambient air quality and cleaner air for Europe, Off. J. Eur. Communities, 152, 1-43, http://eur-lex.europa.eu/LexUriServ/LexUriServ.do? uri=OJ:L:2008:152:0001:0044:EN:PDF (last access: 12 September 2017), 2008.

Gerboles, M., Lagler, F., Rembges, D., and Brun, C.: Assessment of uncertainty of $\mathrm{NO}_{2}$ measurements by the chemiluminescence method and discussion of the quality objective of the $\mathrm{NO}_{2}$ European Directive, J. Environ. Monit., 5, 529-540, https://doi.org/10.1039/b302358c, 2003.

Gist, G. L. and Burg, J. R.: Benzene - a Review of the Literature from a Health Effects Perspective, Toxicol. Ind. Health, 13, 661714, https://doi.org/10.1177/074823379701300601, 1997.

Haley, T. J.: Evaluation of the health effects of benzene inhalation, Clin. Toxicol., 11, 531-548, https://doi.org/10.3109/15563657708988218, 1977.

Hayden, K. L.: Partitioning of reactive atmospheric nitrogen oxides at an elevated site in southern Quebec, Canada, J. Geophys. Res., 108, 4603, https://doi.org/10.1029/2002JD003188, 2003.

Kelessis, A. G., Petrakakis, M. J., and Zoumakis, N. M.: Determination of benzene, toluene, ethylbenzene, and xylenes in urban air of Thessaloniki, Greece, Environ. Toxicol., 21, 440-443, https://doi.org/10.1002/tox.20197, 2006.

LeBouf, R. F., Slaven, J. E., and Coffey, C. C.: Effect of calibration environment on the performance of direct-reading organic vapor monitors, J. Air Waste Manage. Assoc., 63, 528-533, https://doi.org/10.1080/10962247.2013.772926, 2013.

Liaud, C., Nguyen, N. T., Nasreddine, R., and Le Calvé, S.: Experimental performances study of a transportable GC-PID and two thermo-desorption based methods coupled to FID and MS detection to assess BTEX exposure at sub-ppb level in air, Talanta, 127, 33-42, https://doi.org/10.1016/j.talanta.2014.04.001, 2014.

Licen, S., Tolloi, A., Briguglio, S., Piazzalunga, A., Adami, G., and Barbieri, P.: Small scale spatial gradients of outdoor and indoor benzene in proximity of an integrated steel plant, Sci. Total Environ., 553, 524-531, https://doi.org/10.1016/j.scitotenv.2016.02.071, 2016.

Miñarro, M. D. and Ferradás, E. G.: Performance evaluation of two commercial chemiluminescence $\mathrm{NO}_{x}$ analysers according to Eu- 
ropean Standard EN 14211, J. Environ. Monit., 14, 383-390, https://doi.org/10.1039/c1em10601e, 2012.

Mouradian, R. F. and Flannery, J. P.: Effect of Oxygen Content on Calibration of Portable VOC Instruments, Am. Ind. Hyg. Assoc. J., 55, 1084-1086, https://doi.org/10.1080/15428119491018385, 1994.

MSA: Photoionization detectors, Technology for detection of Volatile Organic Compounds, http://media.msanet.com/ NA/USA/PermanentInstruments/GasSensorsTransmitters/

SaveToxSafeVOC/07-2092WhitePaperPID.pdf (last access: 24 June 2017), 2005.

Peng, F., Luoa, T., Yuan, Y., and Qiu, L.: Performance of optimized TVOCs sensor, Procedia Eng., 7, 392-398, https://doi.org/10.1016/j.proeng.2010.11.064, 2010.

Romero-Trigueros, C. R., Miñarro, M. D., Duperón, E. G., Marzal, F. J., and Ferradás, E. G.: Study of the effect of sample pressure on in situ BTEX chromatographs, Environ. Monit. Assess., 188, 665, https://doi.org/10.1007/s10661-016-5674-8, 2016.

Smith, M. T.: Advances in Understanding Benzene Health Effects and Susceptibility, Annu. Rev. Publ. Health, 31, 133148, https://doi.org/10.1146/annurev.publhealth.012809.103646, 2010 .
Steinbacher, M., Zellweger, C., Schwarzenbach, B., Bugmann, S., Buchmann, B., Ordóñez, C., Prevot, A. S. H., and Hueglin, C.: Nitrogen oxide measurements at rural sites in Switzerland: Bias of conventional measurement techniques, J. Geophys. Res.-Atmos., 112, 1-13, https://doi.org/10.1029/2006JD007971, 2007.

Villanueva, F., Notario, A., Mabilia, R., Albaladejo, J., Cabanas, B., and Martínez, E.: Intercomparison of tropospheric $\mathrm{O}_{3}$, benzene and toluene measured by a commercial doas system and conventional monitoring techniques, Fresenius Environ. Bull., 21, 4040-4050, 2012.

von Schneidemesser, E., Monks, P. S., and Plass-Duelmer, C.: Global comparison of VOC and $\mathrm{CO}$ observations in urban areas, Atmos. Environ., 44, 5053-5064, https://doi.org/10.1016/j.atmosenv.2010.09.010, 2010.

Wilson, K. L. and Birks, J. W.: Mechanism and elimination of a water vapor interference in the measurement of ozone by UV absorbance, Environ. Sci. Technol., 40, 6361-6367, https://doi.org/10.1021/es052590c, 2006. 